\title{
L. On the use of chilled cast iron for permanent magnets
}

\section{Albert Campbell B.A.}

To cite this article: Albert Campbell B.A. (1906) L. On the use of chilled cast iron for permanent magnets, Philosophical Magazine Series 6, 12:71, 468-472, DOI: $10.1080 / 14786440609463559$

To link to this article: http://dx.doi.org/10.1080/14786440609463559

曲 Published online: 16 Apr 2009.

Submit your article to this journal ๘

Џ Article views: 2

Q View related articles ¿ 
(10) For the same frequency, initial fux-density, and material, increase of diameter of the specimen increases the critical distance, has little or no effect on the critical retardation (hence making $d \theta / d x$ near the origin less), and diminnishes the leakage coefficients : in fact, we find that the critical distance is approximately proportional to the diameter, and the critical value of the leakage coefficient inversely proportional to the diameter. (See $§ 14$ and Tables XXI., XXIII., XXIV.)

(11) For the same specimen and initial flux, increase of frequency increases the initial value of $d \theta / d x$, increases the critical values of the retardation and the leakage coefficient, and slightly diminishes the critical distance. (See figs. 1, 2, and the Tables.)

(12) For the same specimen and frequency, increase of initial flux increases the critical distance (see fig. 4), increases the critical value of the retardation (fig. 4), and reduces the critical value of the leakage coefficient (see fig. 5): also for low values of the initial flux $\mathrm{F}_{0}, d \theta / d x$ near the origin increases with $F_{1}$, but seems to approach an upper limit for high values of $\mathrm{F}_{0}$. (See fig. 4.)

L. On the Use of Chilled Cast Iron for Permanent Magnets. By Albert Campbell, B.A. (From the National Physical Laboratory.)*

GARLY in the past year an interesting paper $\dagger$ was D published by Mr. B. O. Peirce of Harvard University, drawing attention to the fact that chilled cast-iron is in many instances a suitable material for permanent magnets. As the subject is of interest to scientific experimenters and of considerable imporlance to instrument makers, I undertook some time ago a short research upon it, with a view, firstly of obtaining some measurements by standard methods, and secondly of finding, if possible, an easy method of chilling the material so as to give good results.

Form of Test Pieces. - The cast iron tested was of ordinary commercial quality and was obtained in the form of rods and rings. The rods, which were of rectangular section, were shaped to dimensions usual in such tests, viz., $10 \mathrm{~cm} . \times$ $1 \mathrm{~cm} . \times 1 \mathrm{~cm}$.

* Communicated by the Physical Society : read January 26, 1906.

† Amer. Acad. Proc. xl. 22. pp. 701-715, April 1905. Dr. Watson has kindly drawn my attention to Mr. J. R. Ashworth's experiments on chilled cast-iron rods (Proc. Roy. Soc. vol. Ixii. p. 210, Dec. 9, 1897); he found that the magnetic quality of these was comparable with that of tungsten steel. 
By using rods of these dimensions it is easy to compare the results with those for various kinds of steel which we have already tested or with those published by Madame Curie * and other observers.

Two rings were tested; they were of rectangular section, their mean diameters being nearly equal $(12.5$ and $13.0 \mathrm{~cm}$.). Their cross-sections, however, were very different, being $1.00 \mathrm{sq} . \mathrm{cm}$. and $6.0 \mathrm{sq} . \mathrm{cm}$. respectively. The object of testing a thick and a thin ring was to find if our method of chilling was effective for the hardening of thick castings.

Heat Treatment.-All the test pieces were heated to $1000^{\circ} \mathrm{C}$. in a gas muffle furnace, the temperature being measured by a thermo-junction in the usual way. Each piece was removed from the furnace and quickly chilled in water at the temperature of the room. As Mr. Peirce has pointed out, great care is necessary in handling the cast iron at this high temperature (so near its melting-point) for it becomes very brittle. For this reason the thick ring was placed in the furnace on a $\mathbf{U}$-shaped piece of wrought iron, it was lifted out by means of this support, and the two were plunged together into cold water. By this method the brittle material could be handled without risk of breakage.

Tests on Rods.-After the chilling, the rods were magnetized to saturation by means of a very strong magnetic field. This was produced by a solenoid consisting of 70 turns with a length of $16 \mathrm{~cm}$. and having a resistance of about $0.1 \mathrm{ohm}$. A large current was sent through this coil by connecting it for a very brief interval to a 50 -volt circuit (by the process commonly known as "flashing"). Each rod was then tested for

(1) The maximum remanent flux density $B$ (at the medial section of the bar).

(2) The coërcivity $\mathrm{H}_{0}$, i.e. the value of the demagnetizing magnetic force required to annul this remanent magnetism.

(1) In order to measure the medial $\mathrm{B}$, a small square search-coil of 20 turns of very fine wire was used; it was just large enough to slip along the rod. The search-coil was connected to a calibrated ballistic galvanometer, and, when the coil was slipped off the rod, the resulting deflexion gave the required $B$ in the usual manner.

(2) The coërcivity was found by Madame Curie's method, as follows:-The magnetized bar was fixed at the centre of a long solenoid, a search-coil being so arranged that it could be

* Bulletin de la Société d'Encouragement pour l'Industrie Nationale, Jan. 1898. 
slipped off the bar from the mid position and replaced without removing the bar from the solenoid. By sending a measured carrent through the solenoid the bar was subjected to a known demagnetizing field. This field was gradually increased until the search-coil when slipped off gave no throw on the galvanometer, thus showing that B had been reduced to zero. The value $\left(\mathrm{H}_{0}\right)$ of the magnetic force when this took place is a good indication of the permanence of the remanent magnetism.

If $\mathrm{H}_{0}$ is large, we should expect the bar to hold its magnetism very obstinately. The following table gives the results for four of the rods (Nos. 1 to 4). For the sake of comparison the corresponding numbers are given for exactly similar rods (M and A) of hardened magnet steel of well known makers, $M$ being supplied by Marcbal of Paris, and $A$ coming from the Allevard Forge.

Table I.

\begin{tabular}{|c|c|c|c|}
\hline Marks. & Material. & $\begin{array}{c}\text { Maximum } \\
\text { Remanence. }\end{array}$ & Coërcivity. \\
\hline No. $1 \ldots . . . .$. & Chilled Cast Iron. & 1775 & $52 \cdot 8$ \\
\hline No. $2 \ldots \ldots \ldots$ & , & 1670 & $48 \cdot 9$ \\
\hline No. $3 \ldots \ldots \ldots$ &, & 1690 & $50 \cdot 4$ \\
\hline No. $4 \ldots \ldots .$. &, & 1850 & $52 \cdot 1$ \\
\hline $\mathrm{M} \ldots \ldots \ldots \ldots$ & Magnet Steel. & 2550 & $55 \cdot 5$ \\
\hline$A$ &, & 2950 & $73 \cdot 0$ \\
\hline
\end{tabular}

The above results show that the hardened cast iron rods are not very much inferior to the ordinary magnet steel (M) either in original strength or in power of resisting demagnetization.

Tests on Rings.-Primary and secondary coils were wound on each of the chilled rings, and the $(\mathrm{H}, \mathrm{B})$ curves shown in fig. 1 were determined by the ordinary ballistic method. In addition to these the coëreivities $\left(\mathrm{H}_{0}\right)$ were found for a number of different values of $B$, and the $\left(\mathrm{H}_{0}, \mathrm{~B}\right)$ curves are also shown.

Fig. 2 gives the $(H, B)$ curves for the thin ring before and after chilling.

We see from tig. 1 that, after chilling, the thick ring is magnetically very similar to the thin one; and thus it is evident that, by the treatment already described, a quite heavy casting can be satisfactorily hardened throughout. 
Chilled Cast Iron for Permanent Magnets.

Fig. 1.

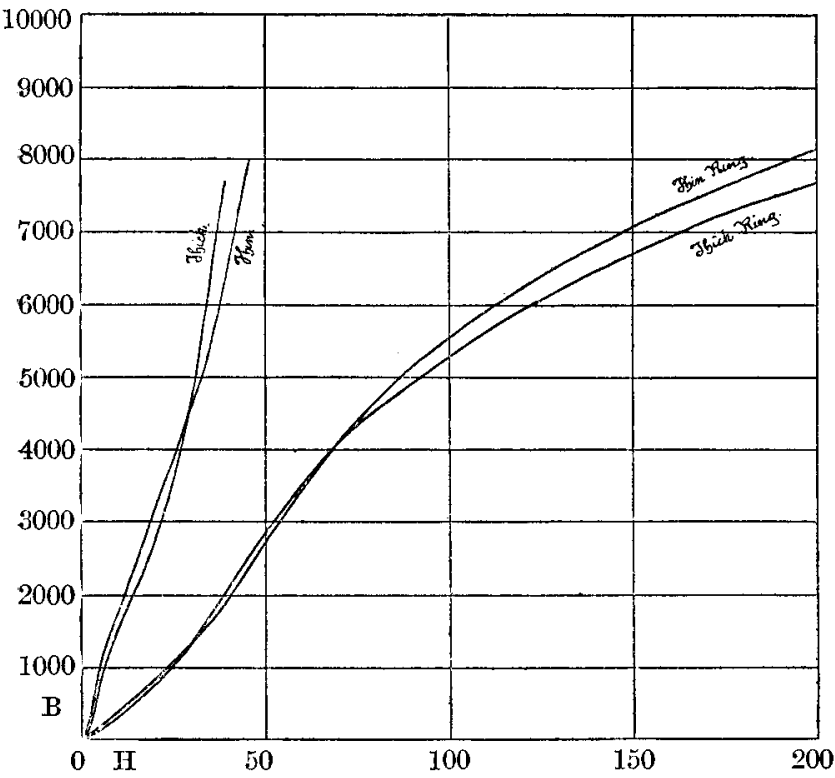

Fig. 2.

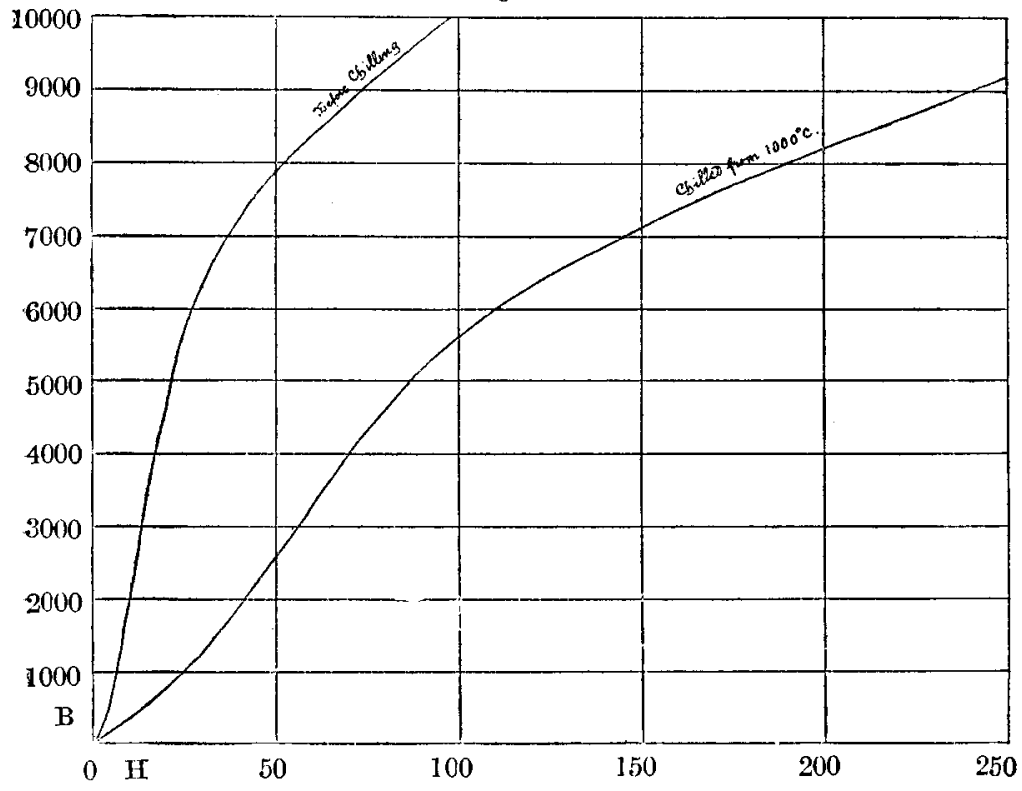


Since the thin ring had the same cross-section as the rods, we may assume that its magnetic hardness was equal to theirs. The experiments here described amply confirm Mr. Peirce's results, and show that large cast iron magnets can be made cheaply and easily; we hope that this short paper will draw the attention of our instrument makers to the matter. In conclusion I would express my thanks to Dr. H. C. H. Carpenter for his kind help in the chilling of the specimens.

LI. The Action of Electrolytes on Colloidal Solutions. By E. F. Bunton, B.A.(Emmanuel College, Cambridge), 1851 Exhibition Science Scholar of the University of Toronto, Research Exhibitioner of Emmanuel College*

\section{Introduction.}

THE study of the coagulative action of comparatively small quantities of electrolytic solutions on irreversible colloidal solutions, besides being of intrinsic interest, has throwa most important light on the mechanism of such solutions; the suggested theories as to the forces which keep the minute particles in suspension in the liquid media rest to a great extent on the behaviour of these particles on the addition of electrolytes.

The importance of the phenomenon was first emphasized by the quantitative experiments of Linder and Picton + ; they determined the coagulative power of different salt-solutions on a colloidal solution of arsenious sulphide, and discovered that this property depended directly upon the valency of the metal of the salt. They found that equivalent solutions containing monovalent, divalent, and trivalent metallic ions possess coagulative powers in the ratio of $1: 35: 1023$. Additional work along the same line has shown that the valency of the metallic ion is important only in the case in which the colloidal particles are negatively charged. In fine, the coagulative power of any electrolytic solution on any colloidal solution depends on the valency of the ion which bears the charge opposite in sign to that on the colloidal particle.

The next fundamentally important step was made by the researches of Hardy $\ddagger$. Working with egg albumen, he found that the direction in which its particles move in an

* Communicated by Professor J. J. Thomson, F.R.S.

$\dagger$ Journ, of Chem. Soc, vol. Ixvii, p. 63. (1903).

I Proc. Roy. Soc. vol. lxvi. p. 110; Jour. of Phys. vol. xxix. p. 26 